\title{
Azure-Kinect and Augmented Reality for learning Basic Mathematics - A case study
}

\author{
Raúl Lozada-Yánez ${ }^{1,2}$, Nora La-Serna Palomino 1, Diego Veloz-Chérrez ${ }^{2}$, Fernando Molina-Granja \\ ${ }^{3}$ \& Juan Carlos Santillán-Lima 4
}

\begin{abstract}
${ }^{1}$ Universidad Nacional Mayor de San Marcos, Facultad de Ingeniería de Sistemas e Informática, raul.lozada@unmsm.edu.pe, nlasernap@unmsm.edu.pe

2 Escuela Superior Politécnica de Chimborazo, fmolina@unach.edu.ec,Riobamba, Ecuador

Facultad de Informática en Electrónica, raul.lozada@espoch.edu.ec, diego.veloz@espoch.edu.ec

3 Universidad Nacional de Chimborazo, Riobamba, Ecuador

Facultad de Ingeniería,fmolina@unach.edu.ec

${ }^{4}$ Universidad Nacional de La Plata, Ciudad de la Plata, Argentina

Facultad de Informática - LEICI - Instituto de Investigaciones en Electrónica, Control y Procesamiento de Señales. Facultad de Ingeniería, jsantillanlima@ext.ing.unlp.edu.ar, juancarlos.santillanl@info.unlp.edu.ar
\end{abstract}

*Correspondence: raul.lozada@espoch.edu.ec; fmolina@unach.edu.ec

\begin{abstract}
The way in which the human being learns certain complex contents has always been a focus of interest and a challenge for researchers. Given the fact that children's cognitive abilities do not fully develop until a certain age, this topic is particularly important in the young children's learning scope as they do not correctly and easily learn some content of abstract nature, such as contents in math class. This work presents the results of the use of an application called "Mathematics Learning System with Augmented Reality based on Kinect" (SAM-RAK by its acronym in Spanish), which was designed to cover basic topics of mathematics in the Basic General Education level (EGB by its acronym in Spanish) in Ecuador. The research was carried out under an experimental quantitative approach with 30 children (18 girls and 12 boys), who study in third grade of EGB level, from 2 different educational institutions in Riobamba city. In order to obtain the results that evaluate the developed application, a pretest and a post-test were applied, which were contrasted with the student's t-test for paired samples. The statistical evidence suggests that the proposed computer system had a positive effect on children's performance, when it was used as a support tool in the classroom. The system was more effective in low performance children compared to those of high performance. It was also proved that children were motivated and showed positive attitudes when using the proposed System.
\end{abstract}

Key words: education, human machine interaction, azure kinect, mathematics.

\section{Introduction}

Despite mathematical experiences are always present in our daily lives, learning some its abstract contents has been a challenging issue at all levels of the education system. This fact takes on greater relevance for school-age children, who have difficulty understanding some content of mathematics, delaying their learning. This scenario also occurs when working with Digital Educational Resources (RED by its acronym in Spanish) since most educational software developers do not consider the particular requirements that arise with this special type of user, who experience physical changes and all important changes in their cognitive abilities due to their age[1][2]. As a result, children cannot easily assimilate much of the content 
of mathematics during the early stages of learning.

Companies in the video game console industry have developed input devices that work on the basis of motion sensors. This type of devices allow users to interact with software using body movements and gestures generally performed with their hands, arms and legs. The interaction with the software becomes simple for users because it is like they were in their daily environment [2]. On the other hand, there is an urgent need to train teachers to handle these types of applications, including topics on behavior analysis strategies [3], and their application in an educational context.

Researchers and application developers have focused in this type of technology and the possibility of having available historical information about the use of these types of resources with computers instead of video game consoles to carry out future research [4]. In fact, there are software tools that allow using these devices with desktop applications to support different areas of human labor.

Replacement of the common input peripherals in a computer system (mouse and keyboard) by motion sensors (such as the one provided in Azure-Kinect) and their combination with augmented reality technology is a new option that can be used in the learning processes. Subjects such as mathematics, have been limited to the presentation of their contents (generally complex and abstract), through static and printed didactic materials, whose analysis requires the use of a high and unnecessary extrinsic cognitive load in students [5] [6]. This problem is even more noticeable in a kid, who perceives this type of educational material as boring and not very motivating. The main aim of this work is to introduce a computer system that improves the usability of digital educational resources and reduces the extrinsic cognitive load to learn mathematics contents for a group of students in third grade of EGB level, by the combination of Augmented Reality technology and the natural interaction mode provided by the Azure-Kinect depth camera.

Students are forced to use the interaction mode that a computer system is equipped (usually a mouse and keyboard), when using Digital Educational Resources. In addition, they must familiarize themselves with managing windows, accessing to menus, learning console commands, specific interfaces of each application and other situations that can vary according to the operating system and the software used. As indicated in [5], an additional cost of learning is generated while students learn to carry out all these interactions by making them use their memory in tasks that are not the pursued objective. This extra and unnecessary load is known as extrinsic cognitive load.

One of the most well-known, studied and important cognitive characteristics of the human being is its limited processing capacity [7]. According to this author, the educational didactic resources, which a student interacts, must be designed taking into consideration the extrinsic cognitive load that these resources generate in users. This evidence indicates the interaction between users and educational resources (digital or not), which transmit the information for the students, is an important aspect that can influence the success of learning processes. Therefore, It is important to reduce the extrinsic cognitive load as much as possible since it saturates, contaminates and affects the working memory of students [8]. Thereby, the working 
memory necessary to process the intrinsic cognitive load[9], which is related to the inherent difficulty of the content that one is trying to learn would increase, cited in [10] [5][7].

As a contribution to achieve all mentioned above, this work presents SAM-RAK, a computerized learning system for basic mathematics, whose main strategy is using a gestural interface provided by the Azure-Kinect depth camera that takes advantage of the cognitive skills and previous knowledge that children have acquired through interaction with the physical world in the course of their lives, in order to reduce the extrinsic cognitive load generated by the use of didactic educational resources with traditional interaction modes (that use mouse and keyboard), [2]. SAM-RAK system combines this mode of interaction with Augmented Reality technology, where users can manipulate and interact with computergenerated digital objects to be integrated into a real environment. This proposed computer system covers contents of basic mathematics and is aimed at children in primary education, specifically for those who are in the third year of EGB level, according to the Ecuadorian educational curriculum.

This research also examines the effect the use of SAM-RAK system causes on the performance of the children participating in the study, also comparing the percentage of improvement that occurred between low-performing and high-performing students.

\section{Literature review}

Despite the fact that mathematics has been called "the language of the universe" [11], human beings generally experience anxiety when learning contents of this subject. This anxiety is largely attributed to the way these contents have traditionally been communicated to students (in a static and even "boring" textbooks). In addition, the abstract nature of their contents encourages more complexity to learning processes because it does not make sense for students, especially for children who are just at the beginning stages of learning of this type of subjects, defined as "complex" since these contents are perceived as a series of rules that must be memorized instead of being understood. Another fact is that learning mathematics is often perceived or even as a punishment, generating in the student demotivation and lack of interest when studying and becoming a difficult task. This lack of interest leads to high dropout rates in the areas of science, technology, engineering and other branches of training that have a strong mathematical basis [12].

Regarding the constructivist approach for learning, in [13], cited by [14], it refers to most of the students gain their knowledge through the sense of sight instead of other senses such as auditory or kinesthetic skills that human beings can use to abstract information from their environment. Seymour Papert (1928-2016), pioneer of technologies leading to current artificial intelligence, based his theory of constructionist learning on the foundations of constructivist theory [15], cited by [16] Under this approach, students develop their own knowledge while designing, constructing, and executing projects proposed in class. Papert used this approach to develop his proposal for a programming language called Logo [17], which he used in the first instance in learning geometry in a constructionist way. 
Computer systems, which offer simulation schemes, are popular in the educational field, mainly because they facilitate the presentation and learning of certain contents that are difficult to understand due to their abstract nature because this property makes difficult to easily understand such contents (both in physical form and in their action and effect) in real life.

Researchers consider that, if the target audience are study school-age children same as the target of this proposed system (specifically those who are in the third grade of EGB according to the Ecuadorian curriculum), the implementation of a learning system that displays mathematics content as a computer game can facilitate the understanding and therefore improve the mathematical learning process [18], cited by [19]. According to [2] this learning process could be further improved if some benefits are included such as the implementation of digital educational resources based on both constructivist educational theory and the combination with Augmented Reality technology and a gestural interface provided by the Azure-Kinect depth camera. In this sense, SAM-RAK was designed to allow General Basic Education children, immersed in an environment, learn in a playful way that, thanks to Augmented Reality, combines computer-generated virtual elements with a view of the real world.

Several investigations have been carried out and indicate applications based on Augmented Reality for learning in mixed interaction environments. In accordance with [20], several factors affect educational effectiveness in solutions that use augmented reality for learning mathematics. In this analysis, a set of theories allows us to understand both the benefits and the limitations of the learning experiences using augmented reality. This research also introduces a framework of reference to understand and address learning based on augmented reality applications from three dimensions:

a) Physical dimension: physical manipulation allows natural interaction with the computer system, and promotes the creation of representations embodied [21] for understanding educational concepts.

b) Cognitive dimension: the right space-time alignment of the information displayed through AR experiences can help to improve the student's symbolic understanding, and

c) Contextual technological dimension: Augmented Reality (AR) technology creates possibilities for collaborative learning (important in the constructivist learning approach), around virtual content. This feature facilitates and encourages meaningful and motivating personal experiences. The results of this work indicate although AR technology shows great potential to expand the resources used to educate there are still questions in this area that must be investigated.

A case that deserves to be mentioned is Construct3D [22] cited in [23], which is a prototype that uses Augmented Reality technology for learning mathematics and geometry and can be used in a individually or in a collaborative mode. Its use improves the spatial skills of high school and university students through geometric constructions. This prototype uses a device mounted on user's head (Head Mounted Display) that integrates a video camera and a stereoscopic screen. It also includes a Personal Interaction Panel (PIP) that a user carries in 
their hands to simplify their interaction modality with the 3D digital models displayed by the system. According to its developers, Construct3D was perceived as a simple tool that covers all the needs of basic geometry teachers. At this educational level, it is not necessary to have a wide variety of complex features such as those of a software of Computer Aided Design (CAD), which are very powerful tools but have a long and gradual learning curve that generates a large extrinsic cognitive load in learners. Construct3D overcomes these difficulties.

\subsection{Azure-Kinect and its applications.}

Azure-Kinect is an electronic device developed by Microsoft that captures human body movements through the RGB camera and the depth sensors it has. This device allows a human being to control a software application without the need for a device that limits their movement because is connected to the computer system. Thus, Azure-Kinect and its natural interaction mode disconnect the user from the hardware, reducing the extrinsic cognitive load using gestures to interact with a computer system. As it can be seen in figure 01, Azure-Kinect is capable of detecting and recognizing 28 anatomical points of a being human unlike previous versions of Kinect (v1, which detected 20 anatomical points and v2, which detected 25 anatomical points) [24].

In general, Azure-Kinect can recognize up to 6 users at the same time. In contrast, its first version just detected and registered 20 anatomical points of the human body and was able to recognize two users simultaneously. Azure-Kinect has been successfully used in various fields of human behavior, including, for example: a) High-quality 3D scanning; b) Human-Computer Interaction; c) Medicine; d) Robotics; e) Sign language translation; f) Virtual Testers.

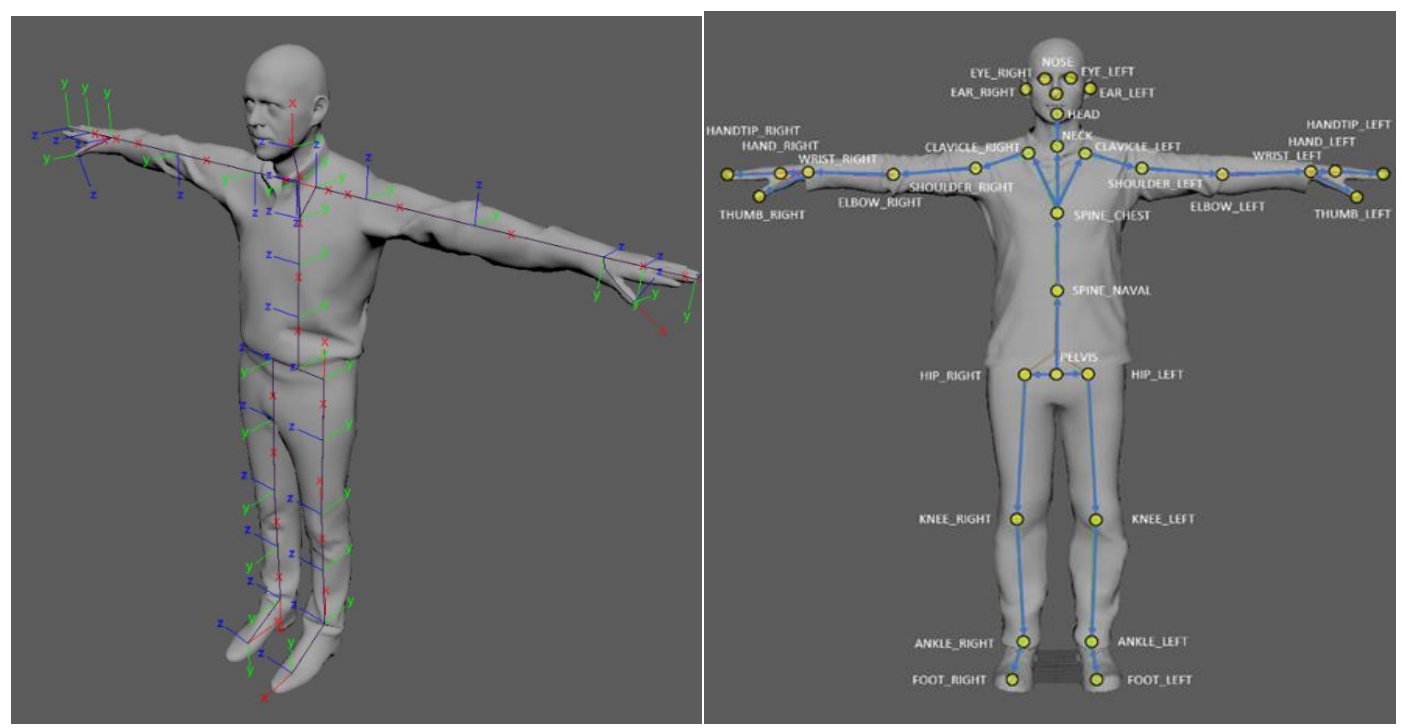

Figure 1. Azure-Kinect recognized anatomical points Source: [24]

According to studies in [25], [2], a special case that deserves attention due to the nature of this work is the use of Azure-Kinect in education, an area where emphasis is placed on the potential of devices that allow natural interaction, especially for K-12 education (elementary and middle school in the United States educational system). Likewise, in [26] cited in [27], 
there is a discussion about the way in which certain commercial games can be used to educate. These studies indicate that using Azure-Kinect and other similar devices introduce new modes of interaction that improve the usability of computer systems that can be applied to support the learning process.

In [28] the following benefits are mentioned by using devices that allow natural interaction of users to operate software:

- Teachers interact with the displayed content through gestures, movements and even voice commands instead of the traditional way (keyboard and mouse).

- The content can be manipulated by up to 6 people simultaneously. This fact stimulates the execution of collaborative activities between students.

- This type of device allows the performance of physical activities, such as dance, martial arts, manipulation of objects that are not possible to performance in real life for any reason.

- Students perceive Azure-Kinect as an interesting and stimulating tool that captures students' attention and keeps them motivated.

The fast popularization of mobile devices and their massive use by people of all ages, by entire families, by educators of all around the world and in particular case by target users in this study, generate new research questions in the scientific community. Regarding to the maturity reached by the tools and technologies on which these proposals are based, these questions arise around the quality of this type of digital teaching resources, their suitability and specific adaptation for the group of users for whom that is directed. It is important to mention that the lack of adaptation in the group target has occurred because most software is developed thinking of a different target audience than children. In this sense, it is well known that the existing techniques and methodologies for software design (educational or not) do not consider the special, specific and changing characteristics children experience in each of the stages of their motor, cognitive, emotional and affective development [2].

This work presents a Learning System for Mathematics with Augmented Reality based on Kinect (SAM-RAK) for third year of Basic General Education to allow the children participating in the study to interact with digital didactic resources by means of hand movements, making use of their hand-eye coordination skills and exercising them at the same time. The system was evaluated through a field test, which consisted in using the system by the children working in pairs with a change of role, being at one point an observer of their partner's activities and at another time interacting with the system .

The main objective of this study is to verify the effect that using this computer application based on Augmented Reality technology and the natural user interaction provided by AzureKinect has on the academic performance of a group of children attending third grade of EGB in two Educational Units in Riobamba, Ecuador. It is expected that the motivation and stimulation provided by the technologies that SAM-RAK is developed, will improve the grades obtained by the group of students participating in the study after using the system. 


\section{Methodology}

According to [29], an appropriate choice of study makes easier to connect the stages of a research process such as the problem statement, the theoretical development and the hypothesis with the subsequent phases, which are more operational. With this consideration in mind, this work uses a quantitative, longitudinal and experimental approach that involves 30 third grade children (18 girls and 12 boys) from 2 Educational Units EGB (Basic General Education in Spanish) level in Riobamba-Ecuador. Researchers evaluate the system developed by applying a pre-test and a post-test. Results were compared with the student's t-test for paired samples. It is important to mention that the samples used were obtained by nonprobability and discretionary sampling since researchers had to find where to carry out the field experiment, having to request the consent of both the authorities of the Educational Units and the children's parents who would participate due to the laws in Ecuador require it when it comes to minors.

\subsection{Justification and preparation for the experiment}

The main objective of the proposed study is to analyze the effect that, using the SAM-RAK system as a support tool, has on the academic performance of the students in mathematics corresponding to the third year of EGB. This system considered three activities for analyzing: "Ordenar, Parear y Sumar" (Order, Match and Add in Spanish). Prior to the development, a meeting was held with the teachers of mathematics to understand and collect the system requirements that they considered SAM-RAK should have based on their experience. In this meeting, the teachers reported that their students were not motivated in math classes and as a consequence, they did not fully understand the contents referring to the topics "Ordenar, Parear y Sumar". Therefore teachers were open and interested in using a technological tool with Augmented Reality technology and natural user interaction to stimulate, motivate and capture the attention of their students in order to improve learning processes. These results were the indicator that motivated the researchers to select and include these specific topics in the developed system.

The results obtained in the stage of pre-test were provided by the teachers who, prior to this evaluation, used traditional resources (textbook and slides) to teach the topics "Ordenar, Parear y Sumar". On the other hand, post-test results were obtained by applying this evaluation to the same group of students using SAM-RAK as a support tool for learning the contents displayed in the computer system. It is important to mention that the activities, evaluated in the pre-test or in the post-test, did not contain the exact items. This fact implies that the selection of the answers required children draw their own conclusions from their knowledge, deduction and exploration of the environment presented in SAM-RAK. These features are foundations of inquiry learning, posture on which the class, used by the system, was designed. It was necessary to make adjustments in the classroom to meet the defined objectives and properly implement the equipment used. These adjustments involved the mobilization of certain furniture to obtain an ideal area of action according to the characteristics recommended for Azure-Kinect (see figure 2). According to Microsoft, this area 
of action was also marked with red adhesive tape to indicate to children that they should stay within the marked area.

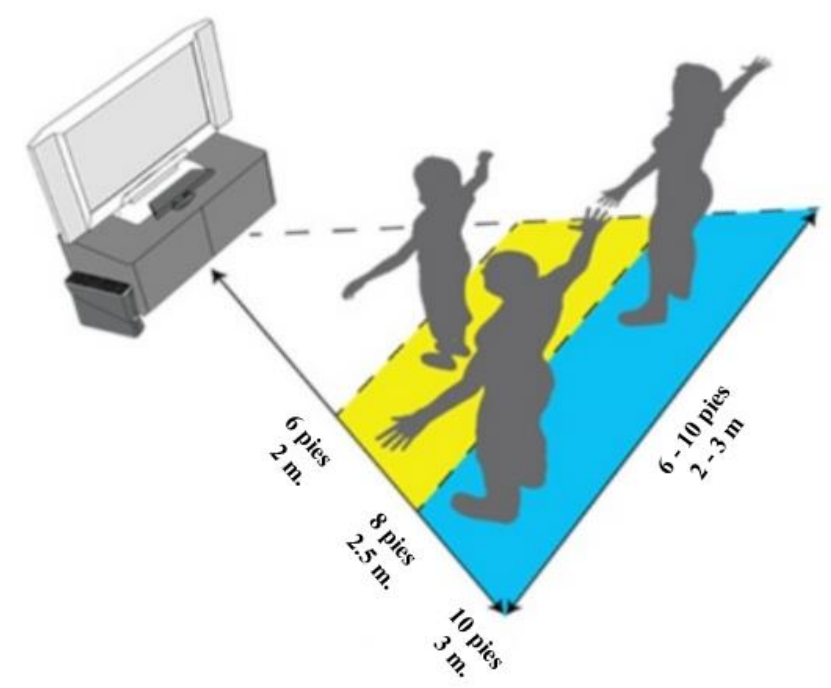

Figure 2. Recommended distance for using Azure-Kinect V2 Source: [24]

The experiment considered the execution of 4 stages, which constitute the experimental design of the study and are detailed in Table 1.

Table 1. Experimental design executed

\begin{tabular}{|l|l|}
\hline \multicolumn{1}{|c|}{$\begin{array}{c}\text { Experiment } \\
\text { phase }\end{array}$} & \multicolumn{1}{c|}{ Methods } \\
\hline $\begin{array}{l}\text { Phase 01. Pre- } \\
\text { test }\end{array}$ & $\begin{array}{l}\text { After receiving classes with traditional media on the contents "Ordenar, } \\
\text { Parear y Sumar", each student had to individually complete a written } \\
\text { test (pre-test) that measured their performance with respect to these } \\
\text { topics. }\end{array}$ \\
\hline $\begin{array}{l}\text { Phase 02. } \\
\text { Training of } \\
\text { working } \\
\text { partners and } \\
\text { use of SAM- } \\
\text { RAK. }\end{array}$ & $\begin{array}{l}\text { After taking the pre-test, the children participating in the study again } \\
\text { received classes on the topics "Ordenar, Parear y Sumar", this time using } \\
\text { the SAM-RAK system. They were randomly grouped into groups of 2 } \\
\text { children to form work teams and then invited to use the tool developed } \\
\text { for a period of 30 minutes, where each child interacted with the activities } \\
\text { proposed for 10 minutes, following the instructions from their teacher, } \\
\text { who briefly (no more than 5 minutes) told them about the Azure-Kinect } \\
\text { mode of interaction through an introductory activity that was prepared } \\
\text { for this purpose. To avoid some kind of bias, the aforementioned } \\
\text { instructions were reflected in a guide that the teacher had to respect and } \\
\text { follow with each pair of children. In this phase, a member of the } \\
\text { researchers was present as a mere spectator of the process carried out by } \\
\text { the children while using and exploring the activities proposed in SAM- }\end{array}$ \\
\hline
\end{tabular}




\begin{tabular}{|l|l|}
\hline & $\begin{array}{l}\text { KAR. The teacher also had the role of indicating to each child when to } \\
\text { change their role (when they were spectators and when they used the } \\
\text { system). }\end{array}$ \\
\hline $\begin{array}{l}\text { Phase 03. Post- } \\
\text { test }\end{array}$ & $\begin{array}{l}\text { After finishing phase 02, each child completed a written test (post-test) } \\
\text { of the same complexity and on the same topics as the pre-test test. }\end{array}$ \\
\hline $\begin{array}{l}\text { Phase 04. } \\
\text { Analysis of }\end{array}$ & $\begin{array}{l}\text { After pre-test and post-test were completed, the results were statistically } \\
\text { contrasted to verify if there was an improvement in the performance of } \\
\text { the participating children after using SAM-KAR and if the difference } \\
\text { recorded was statistically significant. Likewise, the results of students } \\
\text { with the lowest performance (14 points or less, where the maximum } \\
\text { mark is equivalent to } 20 \text { points) were compared with those who } \\
\text { demonstrated a better performance (14 or more) before using the system } \\
\text { developed in this work. }\end{array}$ \\
\hline
\end{tabular}

Made by: The authors

\subsection{Instruments used}

The experimental design, applied in pre-test and post-tests, has been used in many investigations that seek to compare the change of a certain metric that occurs as a result of the implementation of interventions or treatments. For this study, this experimental design was selected since researchers wanted to monitor the effect of using the SAM-KAR system has on children (attending the third year of GBS) participating in this experiment. To validate the tests, they were analyzed and evaluated by a group of 5 teachers with university degrees in mathematics that reviewed the items of both the pre-test and the post-test, evaluating the clarity, relevance and pertinence of the 32 questions that were part of both tests. In order to verify the consistency of the evaluations, a pilot test was carried out, considering the recommendations by the aforementioned experts. Twenty students, who attend the fifth year of EGB (12 boys and 8 girls), took the test, performing the following phases:

- Construction phase. Despite the fact that the research initially considered using a test prepared by the classroom teachers, the researchers considered that it should be validated by other math teachers working in each participating Educational Unit. A secondary-level math teacher also joined this group of teachers for judging and validating pre-test and posttest process.

- Validation of the judges. The 32 items of each evaluation were organized by topic (Ordenar, Parear y Sumar) in a notebook and were submitted to the evaluating experts so that they could determine the clarity, relevance and pertinence of each questions through the criterion of the Content Validity Ratio (CVR) [30]. The use of this criterion allows obtaining the Content Validity Index (CVI) of the entire instrument. As indicated in [31] in order to determine that an item is acceptable, each item must be validated and the CVI index must be greater than 0.5823 . Therefore, all those items with values lower than 0.5823 must be considered for their modification or elimination in order to take care of the quality of the test.

- Test settings. According to the criteria presented in [32] cited in [33], Items, which reported 
unsuitable CVR values obtained in the validation phase, were modified taking into account the recommendations of the judges.

- Execution of the pilot test. One of the validated tests was given to 20 fifth-grade EGB students, who took the assessment in their classroom and had 80 minutes to complete it.

- Reliability analysis. After analyzing the results in the pilot test, the researchers decided to run an internal consistency analysis since it was not possible to carry out a double application method. This analysis was conducted using the Split-Half method (split halves or binary partition), obtaining a reliability coefficient greater than 0.9 . According to the interpretation of [34] this value indicates that if it were possible to apply the test for the first time to the same group of students for 100 occasions, hierarchical grading table, from highest to lowest grade using this method, would come out in the same order more than 90 times.

The results obtained in the instrument validation process confirm the clarity, relevance and relevance of the 32 objective questions of the pre-test as well as the post-test. In addition, both instruments had the same complexity without any repeated question, according to the criteria of the reviewing judges. This group of experts also reported that the tests appropriately and proportionally cover the three topics that were selected to develop the SAM-KAR system.

\subsection{System development}

SAM-KAR is a system that works with Augmented Reality technology and uses the AzureKinect depth camera as an interaction mode, making possible for children to interact with virtual elements generated by computer without the need to use Augmented Reality markers or any electronic device that attaches them to the computer and restricts their movements. The system introduces three specific learning activities to cover the topics: "Ordenar, Parear y Sumar", including one introductory activity, whose main objective was to guide children on how Azure-Kinect would allow them to interact with the software. In this sense, gestures made by the children (specifically, certain movements of their hands) were used for their interaction with the augmented virtual objects in the SAM-KAR system.

- Design Considerations. The design of the system was based on an approach to the constructivist educational model centered on the student and the approach to inquiry learning [35] cited in [36], where the participating boys and girls were randomly grouped into 15 pairs for using the SAM-KAR system, as already mentioned in phase 02 of the experimental design, detailed in Table 1 . It is important to mention that the interaction of the children with the activities, proposed in the system, was performed as if they were working with real world objects due to to the use of Augmented Reality and the natural interaction provided by the Azure-Kinect depth sensor. This combination takes advantage of the previous knowledge of children and reducing the extrinsic cognitive load in the execution of the proposed activities [37]. In another angle of the design of the system, the researchers decided to implement the games with simple functionalities that cover the most common contents of mathematics perceived as not correctly assimilated by the children according to their teachers. With this in mind, it was decided to implement three 
educational activities at SAM-KAR, as detailed below:

1. "Ordenar" activity: For this activity the child must order a set of objects that are presented in disorder according to their size. The order requested can be from larger to smaller or vice versa in order to complete the task. The child moves the objects by dragging (grabbing and moving) and placing them (place and drop) in the corresponding box (see figure $6 \mathrm{~b}$ ).

2. "Parear" activity: In this activity, each child had to associate several sets of elements with their respective numerical representation, drawing a line that adequately connects each number shown with the corresponding element (see figure $6 \mathrm{c}$ ).

3. "Sumar" activity: This activity shows the child a set of elements placed on the left of the screen and there are two boxes placed one on top of the other on the right of the screen, where they can add elements by dragging and dropping and making the box, where they place an object, increases its numerical value by one and then the result of the addition of both boxes is displayed in a third box placed below the first two (see figure $6 \mathrm{~d})$.

In the same way, it was also considered that the proposed system should have some flexibility in terms of the contents that shows, so that the teacher can adapt the system in a certain way according to their criteria. These options will be mentioned later.

- Tools used for the development of the system: Options, used to develop the SAM-KAR system, were: Libfreenect (http://openkinect.org), OpenNI (https://github.com/OpenNI) and Azure Kinect DK (https://azure.microsoft.com / en-en / services / kinect-dk /). For the case study, it was useful to use Libfreenect for receiving raw data from Azure-Kinect. Open source software OpenNI allowed the recognition of children's hands, while Azure Kinect DK is a complete development framework that does everything else from processing raw information (audio, RGB images and depth images), to advanced processes such as simultaneous tracking of 6 users or face tracking and recognition.

Table 2. Feature comparison of available tools for development with Azure-Kinect

\begin{tabular}{|l|c|c|c|}
\cline { 2 - 4 } \multicolumn{1}{c|}{} & Libfreenect & Azure Kinect DK & OpenNI \\
\hline License & $\begin{array}{c}* \text { Apache v2/GPL } \\
\text { v2 }\end{array}$ & Privative & ${ }^{*}$ Apache v2 \\
\hline $\begin{array}{l}\text { Programming } \\
\text { Language }\end{array}$ & $\begin{array}{c}* \text { Linux, OSX, } \\
\text { Windows }\end{array}$ & Windows 10 & $\begin{array}{c}{ }^{*} \text { Ubuntu 12.04+, } \\
\text { Linux Mint 12+ }\end{array}$ \\
\hline Recording & $\begin{array}{c}* \text { C++, C\#, Python, } \\
\text { Javascript }\end{array}$ & C++. & $\begin{array}{c}\text { C, with wrappers } \\
\text { for C++ and Java }\end{array}$ \\
\hline Skeleton Tracking & Yes & ${ }^{*}$ Yes & ${ }^{*}$ Yes \\
\hline Gesture recognition & No & ${ }^{*}$ Yes & ${ }^{*}$ Yes \\
\hline Calibration & No & $\begin{array}{c}* \text { It is possible to } \\
\text { create gestures }\end{array}$ & $\begin{array}{c}* \text { Predefined } \\
\text { gesture sets }\end{array}$ \\
\hline
\end{tabular}

Made by: The authors 
After analyzing the tools as well as their technical features and the support for the development of the system, the set of technological tools, shown in figure 3 , was decided to use for implementing SAM-KAR system.

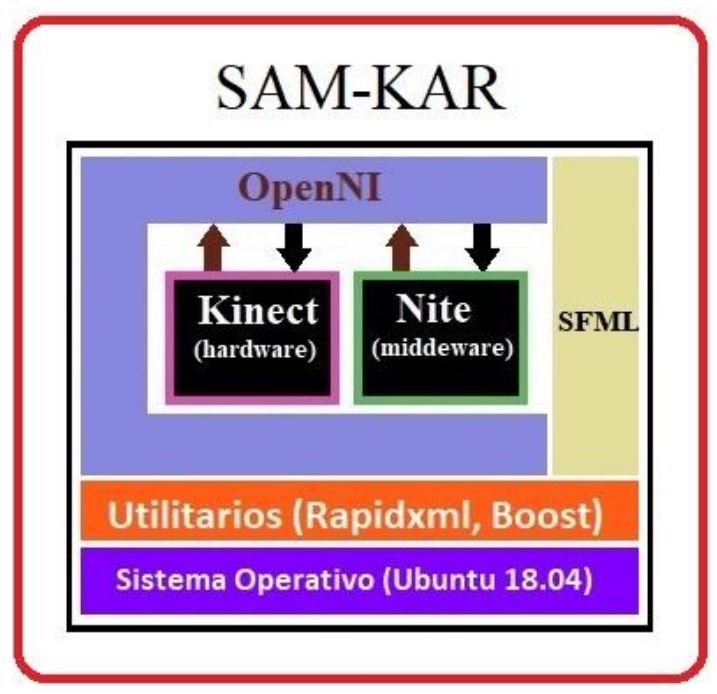

Figure 3. Technologies used for SAM-KAR system development

Made by: The authors

- Human-Computer Interaction: The tools selected for the development of the system do not define the manner of interaction between users and SAM-KAR. For this reason, the interaction mode must be considered and designed according to the defined scenario. As shown in figure 4, many applications, using gestures as a mode for human-computer interaction, operates with the movements of user's hands as a mouse pointer, which is represented on the display device used by each system. A natural interaction environment uses certain gestures and movements of the user to indicate actions and / or execute commands as well as in a traditional interaction environment that uses a mouse to move a pointer across the screen and click or double click to indicate an action and / or execute a command. For this particular case, the system works through detection and monitoring of both children's hands.

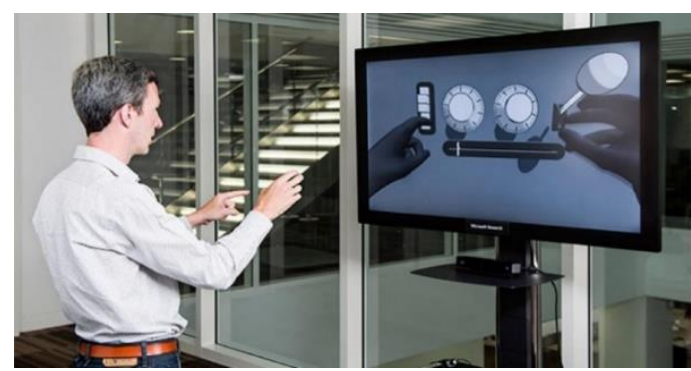

Figure 4. PathSync Interaction Metaphor (Carter et al., 2016).

Source: https://computerhoy.com

The free software tool OpenNI supports certain predefined gestures, which were useful for 
SAM-RAK. To initiate interaction with the system, the child must perform a "hello" gesture and to activate the different buttons on the interface. "Hello" gesture is performed by moving the hand horizontally several times and movement must travel at least $15 \mathrm{~cm}$. On the other hand, the "click" gesture is performed by bringing the open hand towards the sensor and then moving it away. The movement must have a travel of at least $10 \mathrm{~cm}$ in both ways. In figure 5 shows several children interacting with a system whose mode of interaction is supported by a Kinect type motion sensor.

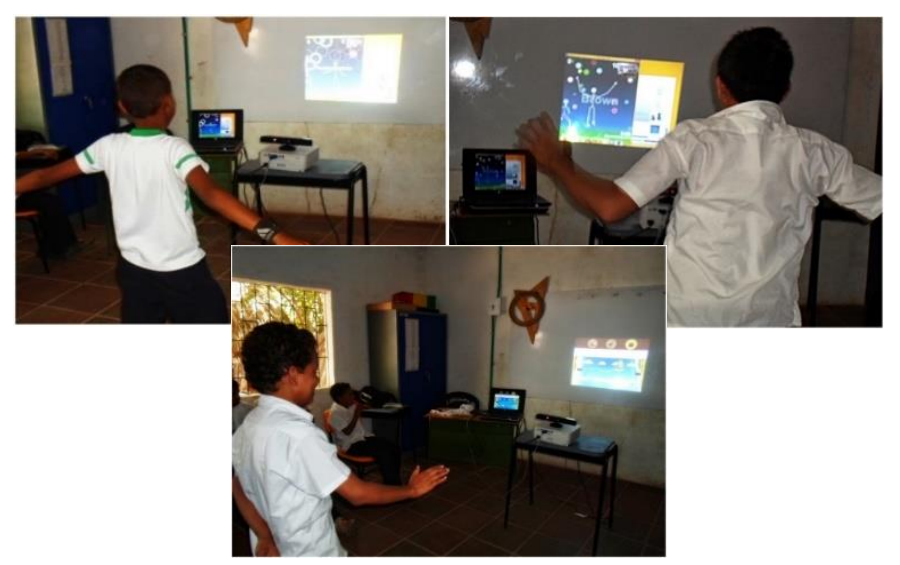

Figure 5. Natural interaction based on Kinect

- The system and its activities: SAM-RAK main screen, shown in figure 6 (a), has buttons that give access to the activities proposed by the system. These buttons are activated with the "click" gesture; Figure 6 (b) shows the "Ordenar" activity; Figure 6 (c) shows the screen of the "Parear" activity and Figure 6 (d) shows the screen that contains the "Sumar" activity. Each of the proposed activities includes two buttons on the top: the back button to return to the main menu while the restart button cancels any progress in the activity by starting it again.
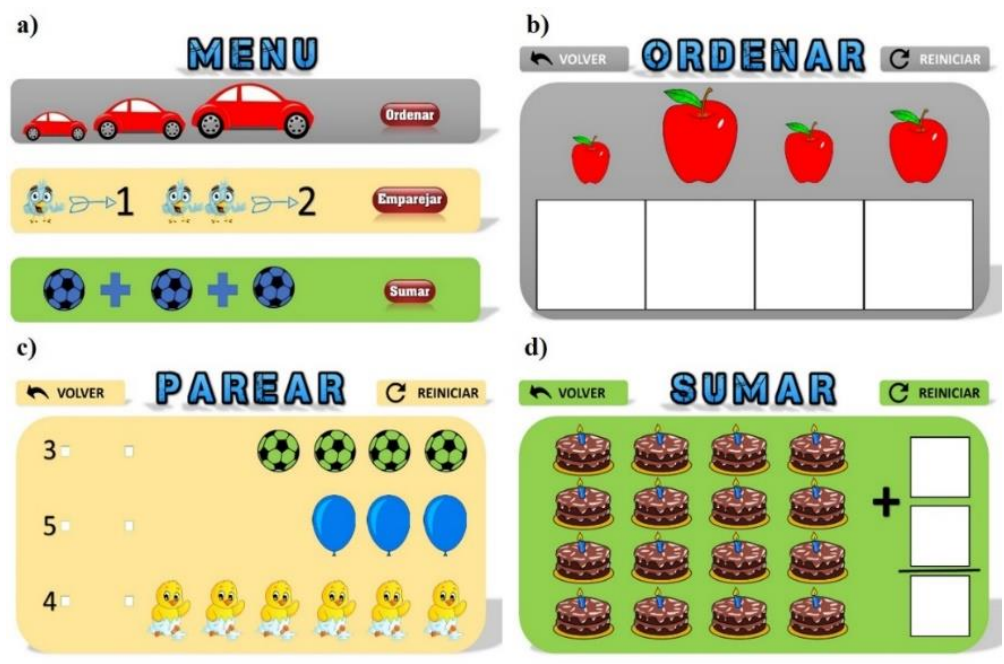

Figure 6. SAM-RAK system screens

Made by: The authors 
As previously mentioned, the developed system has the possibility of being configured in terms of different aspects. The options that can be configured in SAM-RAK are listed below:

- The minimum and maximum ranges for the number of elements that are used in the activities.

- The images that are loaded in each game (they must be in JPG format and have no background).

Customization of these options is done by modifying some files that are read when the application runs. Each of the activities has its own characteristics and, therefore, each one has its configuration file. This file is displayed in the folder "/config" of the system installation folder. It should be noticed that for the "Ordenar" activity, software resizes the images so, to personalize them it is necessary to replace them only once.

Evaluation: To perform the evaluation of the system, a field test was carried out in two Basic Education Units in Riobamba, Ecuador. Student's t-test was used for related samples, which determined if there was statistically significant difference between average grades obtained by the children participating in the study when they learned "Ordenar", "Parear" and "Sumar", practicing on these topics in a traditional way (using their textbook) and the scores obtained by the same group of children, after using the SAM-RAK system (based on AR and natural user interaction). From collected data, the percentages of children improvement were also compared between low performance (less or up to 14 points) and high performance (more than 14 points) groups in the pre-test.

\section{Results and discussions}

After executing the tests, 60 scores were obtained (30 from the pre-test and 30 from the posttest), where 32 points is the maximum achievable grade. The average of the scores, obtained by the children before and after using the SAM-RAK system, were compared by the student's t-test for paired samples. Differences between the averages of the pre-test and the post-test were evaluated to verify the importance. The results obtained by the children in these tests are shown in Table 3.

Table 3. Scores obtained in pre-test / post-test

\begin{tabular}{|c|c|c|c|c|c|}
\hline Subject $\mathbf{N}^{\circ}$ & $\begin{array}{c}\text { Before } \\
\text { SAM-RAK }\end{array}$ & $\begin{array}{c}\text { After } \\
\text { SAM-RAK }\end{array}$ & ${\text { Subject } \mathbf{N}^{\circ}}^{\text {BAM-Rere }}$ & $\begin{array}{c}\text { Beforer } \\
\text { SAM-RAK }\end{array}$ & $\begin{array}{c}\text { After } \\
\text { SAM-RAK }\end{array}$ \\
\hline 1 & 12 & 17 & 16 & 18 & 25 \\
\hline 2 & 23 & 31 & 17 & 21 & 29 \\
\hline 3 & 24 & 32 & 18 & 19 & 27 \\
\hline 4 & 20 & 24 & 19 & 21 & 28 \\
\hline 5 & 20 & 28 & 20 & 20 & 23 \\
\hline 6 & 34 & 28 & 21 & 21 & 30 \\
\hline 7 & 21 & 30 & 22 & 22 & 25 \\
\hline
\end{tabular}




\begin{tabular}{|c|l|l|l|l|l|}
\hline 8 & 15 & 30 & 23 & 26 & 29 \\
\hline 9 & 22 & 27 & 24 & 23 & 27 \\
\hline 10 & 26 & 22 & 25 & 22 & 24 \\
\hline 11 & 17 & 22 & 26 & 23 & 32 \\
\hline 12 & 28 & 33 & 27 & 19 & 31 \\
\hline 13 & 28 & 29 & 28 & 18 & 24 \\
\hline 14 & 18 & 24 & 29 & 13 & 25 \\
\hline 15 & 23 & 25 & 30 & 25 & 24 \\
\hline
\end{tabular}

Made by: The authors

Before carrying out the statistical test, the set of data shown in Table 3 was analyzed. This analysis showed that the samples are continuous quantitative data, the samples have 30 or fewer elements, the population standard deviation is unknown, variances are considered equal since the samples come from the same population and the samples conform to a normal distribution, which was verified using the Shapiro Wilk normality test and the real complement statistics [38] for Excel (see table 4).

Table 4. Shapiro Wilk test to verify normality

\begin{tabular}{|c|c|c|c|}
\hline \multirow{2}{*}{\multicolumn{2}{|c|}{$\begin{array}{c}\text { Shapiro-Wilk test } \\
\text { pre-test }\end{array}$}} & \multirow{2}{*}{\multicolumn{2}{|c|}{$\begin{array}{c}\text { Shapiro-Wilk test } \\
\text { post-test }\end{array}$}} \\
\hline & & & \\
\hline W-stat & 0,96984629 & W-stat & 0,96073391 \\
\hline p-value & 0,53497754 & p-value & 0,32340501 \\
\hline alpha & 0,05 & alpha & 0,05 \\
\hline normal & yes & normal & yes \\
\hline
\end{tabular}

Made by: The authors

Conclusion of normality tests.

Before SAM-RAK: With a certainty of $95 \%$, there is no statistical evidence that indicates data obtained in the pre-test are not normal.

After SAM-RAK: With a certainty of $95 \%$, it can be stated that there is no statistical evidence that indicates data obtained in the post-test are not normal.

After the necessary conditions were verified in each sample, it was determined that the probability distribution would be the one-tailed student's t-test for related samples with a confidence level of $95 \%$ (alpha $=0.05$ ). This test allows determining if there is a statistically significant difference between the average scores obtained by children before and after using SAM-RAK. The results of the Student's $t$ test are shown in Table 5. 
Table 5. Student t-test results for related samples

\begin{tabular}{|l|l|l|l|l|}
\hline \multicolumn{2}{|l|}{ SUMMARY } & Alpha & $\mathbf{0 , 0 5}$ \\
\cline { 1 - 2 } Groups & Counting & Average & $\begin{array}{l}\text { Standard } \\
\text { deviation }\end{array}$ & $\begin{array}{l}\text { t- } \\
\text { calculation }\end{array}$ \\
\hline post-test & 30 & 16.77 & 2.2807 & 6.6466 \\
\cline { 1 - 2 } pre-test & 30 & 13.38 & 2.8219 & \\
\cline { 1 - 3 } Difference & 0 & 3.4 & 0.5412 & \\
\hline
\end{tabular}

\begin{tabular}{|l|l|l|l|l|l|}
\cline { 2 - 6 } \multicolumn{1}{c|}{} & p-value & t-critical & Inferior & Superior & Significance \\
\hline One tailed & $1,3742 \mathrm{E}-07$ & 1,6991 & 2,35090 & 4,4407 & $\mathrm{Si}$ \\
\cline { 2 - 3 } Two tailed & $2,7485 \mathrm{E}-07$ & 2,0452 & & & $\mathrm{Si}$ \\
\hline
\end{tabular}

Made by: The authors

The data found in this statistical analysis for $\mathrm{t}$-value calculated and critical $\mathrm{t}$-value of one tailed $(\mathrm{t}$-calculated $=6.6466 ; \mathrm{t}$-critical $=1.6991)$ and the $\mathrm{p}$-value $=1.3742 \mathrm{E}-07$, indicate that we must reject the null hypothesis of the test (Ho -> There is no difference between the average of the samples). Therefore, with a 95\% confidence level, we can determine that the difference between the averages obtained before (13.38) and after (16.77) using the SAM-RAK system is statistically significant and the observed improvement is due to the use of the system presented and implemented by the study and that this difference is not a random result.

This analysis allows comparing the importance of improvement of the group of children considered as low performing with the level of improvement of the group of high performing children. Table 6 shows the scores obtained by the children before and after using SAM-RAK, separated into two groups (low and high performance). These ratings are presented on a scale in which the maximum score, that is, 32 , is equal to 20 points. 
Table 6. Children separated into high and low performance groups

\begin{tabular}{|c|c|}
\hline \multicolumn{2}{|c|}{ SCORES } \\
\hline Before & After \\
\hline 7,50 & 10,63 \\
\hline 8,13 & 15,63 \\
\hline 9,38 & 18,75 \\
\hline 10,63 & 13,75 \\
\hline 11,25 & 15,00 \\
\hline 11,25 & 15,63 \\
\hline 11,25 & 15,00 \\
\hline 11,88 & 16,88 \\
\hline 11,88 & 19,38 \\
\hline 12,50 & 15,00 \\
\hline 12,50 & 17,50 \\
\hline 12,50 & 14,38 \\
\hline 13,13 & 18,75 \\
\hline 13,13 & 18,13 \\
\hline 13,13 & 17,5 \\
\hline 13,13 & 18,75 \\
\hline 13,75 & 16,88 \\
\hline 13,75 & 15,63 \\
\hline 13,75 & 15,00 \\
\hline
\end{tabular}

\begin{tabular}{|c|c|c|}
\hline \multicolumn{2}{|c|}{ SCORES } & \multirow{13}{*}{ 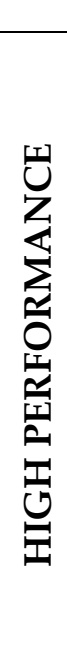 } \\
\hline Before & After & \\
\hline 14,38 & 19,38 & \\
\hline 14,38 & 15,63 & \\
\hline 14,38 & 16,88 & \\
\hline 14,38 & 20,00 & \\
\hline 15,00 & 20,00 & \\
\hline 15,63 & 15,00 & \\
\hline 16,25 & 13,75 & \\
\hline 16,25 & 18,13 & \\
\hline 17,50 & 20,63 & \\
\hline 17,50 & 18,13 & \\
\hline 21,25 & 17,50 & \\
\hline
\end{tabular}

Made by: The authors

The average obtained by the children of the low-performance group was 11.81 points before using the system and the average after using SAM-RAK was 16.22 points, with 20 points being the maximum score. Accordingly, the percentage of improvement (which was 4.41 points) in this group of children was $22.04 \%$. On the other hand, the group of high-performance obtained an average of 16.08 points before using the system, while the average obtained after using SAM-RAK, as a reinforcement tool, was 17.73 points These results allow determining that the percentage of improvement (which was 1.65 points) was $8.23 \%$ for this group. Therefore, these results indicate that the computer tool implemented caused more significant gains in learning for the group of children with low performance than in the group with high performance.

It was observed that most of the children did not have interaction problems with the software when using SAM-RAK, a fact that demonstrates the low extrinsic cognitive load generated by the applications that base their operation on natural user interfaces. This factor helped children have a better understanding of the purpose of each game. Despite this, on very few occasions, teachers had to intervene and help the children to complete any of the activities (it was never more than one). It is important to indicate that difficulties observed in these cases were errors executing commands, for instance, infants involuntarily activated one of the upper buttons on the screen when executing the gestures, causing the activity to restart or to abandon the activity they were trying to develop. 
Using an alternative to replace the buttons on the top can solve this problem. An option may be to implement a screen that is showed in a separate window from the main application. Teachers could control the navigation and restart the activities from this new screen.

In the "Ordenar" game, a direction was missing and children did not know which way they should order the virtual elements displayed, that is, if they should start from the left or from the right. Children were not very stimulated by The "Sumar" activity. This may be because this activity does not have an end goal like the other activities. A solution for this problem could be to include an objective for this activity. For example, the teacher could indicate the desired addends and the child would place the corresponding objects in the right boxes. Another alternative could be to indicate the number of addends by filling in the boxes that display the numbers.

\section{Conclusions}

The analysis of the data obtained in the experiment allowed determining the existence of a statistically significant difference between the scores obtained by the children in the test that measures their performance after using SAM-RAK compared to their scores obtained before using the proposed system.

The analysis carried out also corroborated that there was a greater improvement in the children with low performance compared to the children of the high performance group. It has been considered that possible reasons for this finding may be: a) many of the scores obtained by the children in the high-performance group are very high. There was even a case in which the highest possible score was obtained. Thus, this makes the space for improving the performance quite limited and b) the test was quite basic and the children in the high performance group were fluent in these topics and it was very easy for them to achieve high marks before and after using SAM-RAK.

During the execution of this study, it was possible to verify what was stated in Hsu (2011), a work that affirms an application based on this type of technology has a high motivational level in students.

Azure-Kinect is an interaction device that presents several possibilities in terms of applications for the educational field. The present study has used the depth map, one of the forms of interaction that Azure-Kinect supports. This fact makes possible to improve certain characteristics such as gesture recognition and gesture tracking. Analysis of other interaction options that this device can offer is a pending task for future studies.

There is a gap in terms of interaction standards with peripherals that do not use controls or commands. It was evidenced the scarce existence of guides, models, frameworks and / or conventions that lead the programmer in the design of applications that use this type of interaction.

The need to study the usability of applications based on devices that use motion sensors instead of controls is highlighted. Applications, such as Azure-Kinect, that consider the 
cognitive abilities of users (especially if they are children) to learn. This analysis must be carried out in order not to underestimate or overestimate users in terms of their abilities and prior knowledge in order to design an effective application.

The potential of these types of systems for the field of education is introduced as a new opportunity for both research and development of future applications. Research can be done on the development of new educational games based on Azure-Kinect that contemplate other contents, other forms of interaction or another types of user.

Heuristics should be developed to help in determining usability of educational games for children, since this group of users have differences if we compare them with users for whom commercial video games are designed.

\section{References}

1. T. Gossen, M. Nitsche, y A. Nürnberger, "Evolving Search User Interfaces", presentado en European Workshop on Human-Computer Interaction and Information Retrieval (EuroHCIR), Dublin, 2013, [En línea]. Disponible en: https://dblp.org/rec/conf/eurohcir/GossenNN13.html.

2. R. Lozada, L. Rivera, y F. Molina, "MS-Kinect in the development of educational games for preschoolers", International Journal of Learning Technology, vol. 13, núm. 4, pp. 277305, ene. 2018, doi: 10.1504/IJLT.2018.098500.

3. Y. F. Khaleel, "Assessing the Knowledge Level of Teachers of Children with Autism Spectrum Disorder about the Importance of Applied Behavior Analysis (ABA) Strategies in Zarka City", International Education Studies, vol. 12, núm. 5, pp. 120-132, 2019.

4. F. Molina y G. D. Rodríguez, "The preservation of digital evidence and its admissibility in the court", International Journal of Electronic Security and Digital Forensics, vol. 9, núm. 1, pp. 1-18, ene. 2017, doi: 10.1504/IJESDF.2017.081749.

5. J. Sweller, "Element Interactivity and Intrinsic, Extraneous, and Germane Cognitive Load", Educ Psychol Rev, vol. 22, núm. 2, pp. 123-138, jun. 2010, doi: 10.1007/s10648010-9128-5.

6. J. Sweller, J. J. G. van Merriënboer, y F. Paas, "Cognitive Architecture and Instructional Design: 20 Years Later", Educ Psychol Rev, vol. 31, núm. 2, pp. 261-292, jun. 2019, doi: 10.1007/s10648-019-09465-5.

7. J. Sweller, "Cognitive load theory, learning difficulty, and instructional design", Learning and Instruction, vol. 4, núm. 4, pp. 295-312, ene. 1994, doi: 10.1016/09594752(94)90003-5.

8. L. A. Lotero, “Teoría de la carga cognitiva, diseño multimedia y aprendizaje: un estado del arte", Magis, Revista Internacional de Investigación en Educación, vol. 5, núm. 10, Art. núm. 10, dic. 2012, doi: 10.11144/Javeriana.m5-10.tccd. 
9. T. S. Chong, "Recent Advances in Cognitive Load Theory Research: Implications for Instructional Designers", (MOJIT), vol. 2, núm. 3, pp. 106-117, 2005.

10. L. Cabañero, R. Hervás, I. González, J. Fontecha, T. Mondéjar, y J. Bravo, "Characterisation of mobile-device tasks by their associated cognitive load through EEG data processing", Future Generation Computer Systems, vol. 113, pp. 380-390, dic. 2020, doi: 10.1016/j.future.2020.07.013.

11. M. Khan, F. Trujano, y P. Maes, “Mathland: Constructionist Mathematical Learning in the Real World Using Immersive Mixed Reality", en Immersive Learning Research Network, Cham, 2018, pp. 133-147, doi: 10.1007/978-3-319-93596-6_9.

12. J. Ellis, B. K. Fosdick, y C. Rasmussen, “Women 1.5 Times More Likely to Leave STEM Pipeline after Calculus Compared to Men: Lack of Mathematical Confidence a Potential Culprit", PLOS ONE, vol. 11, núm. 7, p. e0157447, jul. 2016, doi: 10.1371/journal.pone.0157447.

13. D. Perkins, “The Many Faces of Constructivism”, Educational Leadership, vol. 57, núm. 3, pp. 6-11, 1999.

14. C. Chen, G. Sonnert, P. M. Sadler, D. Sasselov, y C. Fredericks, “The impact of student misconceptions on student persistence in a MOOC", Journal of Research in Science Teaching, vol. 57, núm. 6, pp. 879-910, 2020, doi: 10.1002/tea.21616.

15. I. Harel y S. Papert, Constructionism. Westport, CT, US: Ablex Publishing, 1991, pp. xi, 518.

16. L. Floridi, The Logic of Information: A Theory of Philosophy as Conceptual Design. Oxford University Press, 2019.

17. S. Papert, Logo philosophy and implementation. Highgate Springs?, VT: Logo Computer Systems, 1999.

18. D. I. Cordova y M. R. de Lepper, "Intrinsic motivation and the process of learning: Beneficial effects of Contextualization, personalization, and choice", Journal of educational psychology, vol. 88, núm. 4, p. 715, 1996, doi: 10.1037/0022-0663.88.4.715.

19. C. Ferguson, E. L. van den Broek, y H. van Oostendorp, "On the role of interaction mode and story structure in virtual reality serious games", Computers $\mathcal{E}$ Education, vol. 143, p. 103671, ene. 2020, doi: 10.1016/j.compedu.2019.103671.

20. K. R. Bujak, I. Radu, R. Catrambone, B. MacIntyre, R. Zheng, y G. Golubski, “A psychological perspective on augmented reality in the mathematics classroom", Computers $\mathcal{E}$ Education, vol. 68, pp. 536-544, oct. 2013, doi: 10.1016/j.compedu.2013.02.017.

21. J.-I. Pozo, "Learning beyond the body: from embodied representations to explicitation mediated by external representations", Journal for the Study of Education and Development, vol. 40, núm. 2, pp. 219-276, abr. 2017, doi: 10.1080/02103702.2017.1306942. 
22. H. Kaufmann, "Construct3D: an augmented reality application for mathematics and geometry education", en Proceedings of the tenth ACM international conference on Multimedia, Juan-les-Pins, France, dic. 2002, pp. 656-657, doi: 10.1145/641007.641140.

23. M. I. S. Guntur, W. Setyaningrum, H. Retnawati, y M. Marsigit, "Assessing the Potential of Augmented Reality in Education", en Proceedings of the 2020 11th International Conference on E-Education, E-Business, E-Management, and E-Learning, Osaka, Japan, ene. 2020, pp. 93-97, doi: 10.1145/3377571.3377621.

24. Microsoft, “Azure Kinect DK documentation", 2020. https://docs.microsoft.com/enus/azure/kinect-dk/ (consultado ago. 08, 2020).

25. L. Johnson, S. Adams, y M. Cummins, “NMC Horizon Report: 2012 K-12”. Austin, TX: New Media Consortium, 2012.

26. M. Kandroudi y T. Bratitsis, "Exploring the Educational Perspectives of XBOX Kinect Based Video Games", In Proceedings of ECGBL 2012 (pp. 219-227)., 2012. https://search.proquest.com/openview/dd5077238a059c968f6669e7723b493c/1?pqorigsite=gscholar\&cbl=396495 (consultado ago. 07, 2020).

27. C. Wu y Q. Zheng, "Motion Sensing Games for Children with Autism Spectrum Disorder", en VR, Simulations and Serious Games for Education, Y. Cai, W. van Joolingen, y Z. Walker, Eds. Singapore: Springer, 2019, pp. 55-65.

28. Z. Tacgin, Virtual and Augmented Reality: An Educational Handbook. Cambridge Scholars Publishing, 2020.

29. R. Sampieri, C. Fernández, y P. Baptista, Metodología de la Investigación, Sexta. México: McGraw-Hill Interamericana, 2014.

30. Y. E. Díaz y L. L. Baez, “Exploración de la capacidad de liderazgo para la incorporación de TICC en educación: validación de un instrumento", RELATEC: Revista Latinoamericana de Tecnología Educativa, vol. 14, núm. 3, pp. 35-47, 2015.

31. A. Tristán-López, "Modificación al modelo de Lawshe para el dictamen cuantitativo de la validez de contenido de un instrumento objetivo", Avances en medición, vol. 6, núm. 1, pp. 37-48, 2008.

32. C. H. Lawshe, "A Quantitative Approach to Content Validity", Personnel Psychology, vol. 28, núm. 4, pp. 563-575, 1975, doi: 10.1111/j.1744-6570.1975.tb01393.x.

33. R. Roig-Vila, A. Lorenzo-Lledó, y S. Mengual-Andrés, "Utilidad percibida de la realidad aumentada como recurso didáctico en Educación Infantil", Campus Virtuales, vol. 8, núm. 1, Art. núm. 1, mar. 2019.

34. J. Rositas, M. H. Badii Zabeh, y J. Castillo, “La confiabilidad de las evaluaciones del aprendizaje conceptual: Índice Spearman-Brown del método split-halves = Reliability of the evaluation of conceptual learning: index of Spearman-Brown and the split-halves method.", Innovaciones de negocios, vol. 3, núm. 6, Art. núm. 6, 2006.

35. M. I. González, Metodología de indagación como proceso de mejora del rendimiento académico 
en matemáticas. Colombia: Ed. Instituto Latinoamericano de Altos Estudios, 2014.

36. H. G. S. Bedoya y V. L. U. López, "La Metodología de la Indagación en la Enseñanza y Aprendizaje de la Matemática", Investigación e Innovación en Matemática Educativa, vol. 4, núm. 1, Art. núm. 1, sep. 2019, Consultado: ago. 09, 2020. [En línea]. Disponible en: http://www.revistaiime.org/index.php/IIME/article/view/53.

37. X. Wei, D. Guo, y D. Weng, "Improving Authentic Learning by AR-Based Simulator", en Image and Graphics Technologies and Applications, Singapore, 2018, pp. 124-134, doi: 10.1007/978-981-13-1702-6_13.

38. C. Zaiontz, "Performing Real Statistical Analysis Using Excel", 2020. http://www.realstatistics.com/ (consultado ago. 10, 2020). 